\title{
Infographic. Benefits and harms of exercise therapy in people with multimorbidity
}

\author{
Alessio Bricca (D) , 1,2 Lasse Kindler Harris, ${ }^{3}$ Madalina Jäger, ${ }_{1}^{2,4}$ Susan Smith, ${ }^{5}$ Carsten B Juhl, ${ }_{1}^{1,6}$ \\ Søren T Skou (D) 2,4
}

\section{MULTIMORBIDITY AND THE PAUCITY OF EFFECTIVE TREATMENTS}

People with multimorbidity (two or more medical conditions) have poorer physical and psychosocial health and higher risk of hospital admission and premature death. ${ }^{1}$ The complexity and increased burden of multimorbidity presents challenges for healthcare systems. ${ }^{2}$ Therefore, the current standard of care for patients with multimorbidity includes visiting many healthcare professionals and reviewing different pharmacological treatments with inherent risk of side effects. This is often unsatisfactory for the patients.

\section{EXERCISE THERAPY FOR PEOPLE WITH MULTIPLE CHRONIC CONDITIONS}
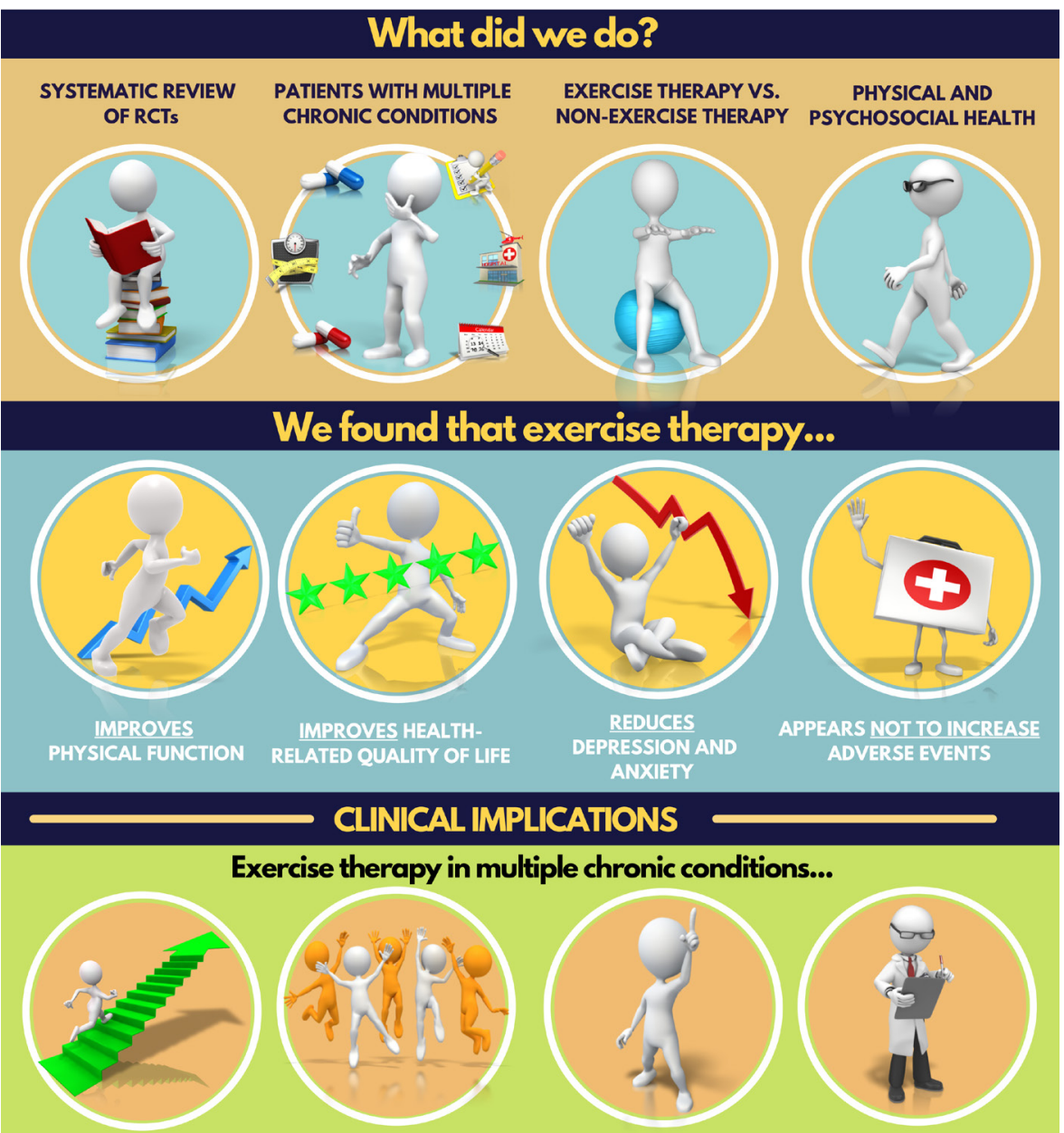

Exercise therapy in multiple chronic conditions...
BENEFITS PHYSICAL HEALTH

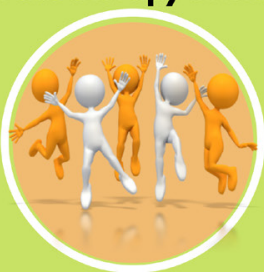

BENEFITS PSYCHOSOCIAL HEALTH

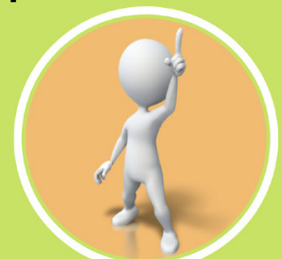

APPEARS SAFE

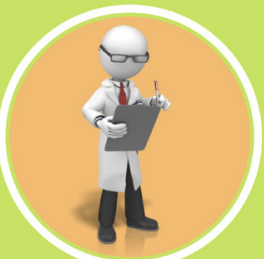

SHOULD BE RECOMMENDED IN CLINICAL PRACTICE
Bricca $A$, Harris $L K$, Jäger M, Smith SM, Juhl CB, Skou ST. Benefits and harms of exercise therapy in people with multimorbidity: A systematic review and meta-analysis of randomised controlled trials. Ageing Res Rev. 2020;63:101166.

erc

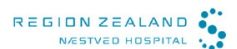

MOBLIZE

regign zealand :

$\because \quad$ SDU
THE POTENTIAL ROLE OF EXERCISE

Exercise is considered a core treatment for at least 26 chronic conditions. However, little is known about its effects in people with multimorbidity. To fill this gap, we performed a systematic review of randomised controlled trials to investigate the benefits and harms of exercise therapy (ie, a regimen or plan of physical activities designed and prescribed for specific therapeutic goals with the purpose of restoring normal physical function or to reduce symptoms caused by diseases or injuries) in multimorbidity. ${ }^{4}$ We included studies with $80 \%$ or more participants having at least two of the following common chronic conditions: osteoarthritis, hypertension, type 2 diabetes, depression, heart failure, ischaemic heart disease and chronic obstructive pulmonary disease. ${ }^{4}$ These conditions are among the leading causes of global disability, often coexist, have shared risk factors and pathogenesis ${ }^{5}$ and have a negative impact on physical and psychosocial health.

\section{BENEFITS AND HARMS OF EXERCISE THERAPY IN PEOPLE WITH \\ MULTIMORBIDITY}

Twenty-three studies from 17 countries examined exercise interventions in different settings and included 3363 people (median age $=65, \mathrm{IQR}=58-71$ ). The most common combinations of conditions were heart failure and depression, type 2 diabetes and depression, and hypertension and type 2 diabetes. The exercise therapy programmes were at least partly supervised, included aerobic and/or strengthening exercise and were performed two to three times a week for 12 weeks (on average).

Exercise therapy improved healthrelated quality of life (standardised mean difference (SMD) $0.37,95 \%$ CI 0.14 to $0.61)$ and objectively measured physical function (SMD 0.33, 95\% CI 0.17 to 0.49 ) and reduced depression (SMD $-0.80,95 \%$ CI -1.21 to -0.40 ) and anxiety symptoms (SMD -0.49 , 95\% CI -0.99 to 0.01 ). Additionally, exercise therapy was not associated with an increased risk of non-serious adverse events (risk ratio $0.96,95 \%$ CI 0.53 to 
1.76), such as musculoskeletal pain and falls. By contrast, it appeared to reduce the risk of serious adverse events such as hospitalisation and pneumonia (risk ratio $0.62,95 \%$ CI 0.49 to 0.78$)^{4}$ (figure 1 ). However, future studies including people with different combinations of conditions, with exercise therapy interventions tailored to people's goals and preferences and selection of primary outcome measures that are important to patients, are needed to improve the confidence in these results.

\section{CLINICAL IMPLICATIONS}

Our systematic review found that exercise therapy seems safe and beneficial for people with multimorbidity (as defined in our study), as for patients with single chronic conditions, hence, it should be considered as a treatment option. People with multimorbidity can expect to improve their psychosocial and physical health by exercising two to three times a week regardless of the combinations of conditions we investigated.

1 Department of Sports Science and Clinical

Biomechanics, University of Southern Denmark, Odense, Denmark

${ }^{2}$ The Research Unit PROgrez, Department of Physiotherapy and Occupational Therapy, NæstvedSlagelse-Ringsted Hospitals, Slagelse, Denmark ${ }^{3}$ Clinical Orthopaedic Research Hvidovre, Københavns Universitetshospital, Copenhagen, Denmark ${ }^{4}$ Research Unit for Musculoskeletal Function and Physiotherapy, Department of Sports Science and Clinical Biomechanics, University of Southern Denmark, Odense, Denmark
${ }^{5}$ HRB Centre for Primary Care Research, Department of General Practice, Royal College of Surgeons in Ireland (RCSI), Dublin, Ireland

Department of Physiotherapy and Occupational Therapy, University Hospital of Copenhagen Herlev and Gentofte, Copenhagen, Denmark

Correspondence to Dr Alessio Bricca, Department of Sports Science and Clinical Biomechanics, University of Southern Denmark, Odense 5230, Denmark; abricca@health.sdu.dk

\section{Twitter Søren T Skou @STSkou}

Contributors $A B$ wrote the first draft of the manuscript and designed the first draft of the infographic. All the authors contributed to revise the final manuscript and infographic

Funding European Research Council (ERC) under the European Union's Horizon 2020 research and innovation programme (MOBILIZE, grant agreement number 801790), Næstved, Slagelse and Ringsted Hospitals' Research Fund and The Association of Danish Physiotherapists Research Fund.

Competing interests None declared.

Patient consent for publication Not required.

Provenance and peer review Not commissioned; externally peer reviewed.

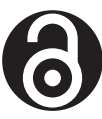

\section{OPEN ACCESS}

Open access This is an open access article distributed in accordance with the Creative Commons Attribution Non Commercial (CC BY-NC 4.0) license, which permits others to distribute, remix, adapt, build upon this work non-commercially, and license their derivative works on different terms, provided the original work is properly cited, appropriate credit is given, any changes made indicated, and the use is non-commercial. See: http://creativecommons.org/ licenses/by-nc/4.0/

(C) Author(s) (or their employer(s)) 2021. Re-use permitted under CC BY-NC. No commercial re-use. See rights and permissions. Published by BMJ.

\section{A) Check for updates}

To cite Bricca $A$, Harris LK, Jäger $M$, et al. Br J Sports Med 2021:55:1059-1060.

Accepted 4 June 2021

Published Online First 9 June 202

Br J Sports Med 2021;55:1059-1060.

doi:10.1136/bjsports-2021-104367

\section{ORCID iDs}

Alessio Bricca http://orcid.org/0000-0001-9717-918X

Søren T Skou http://orcid.org/0000-0003-4336-7059

\section{REFERENCES}

1 Vogeli C, Shields AE, Lee TA, et al. Multiple chronic conditions: prevalence, health consequences, and implications for quality, care management, and costs. J Gen Intern Med 2007;22 Suppl 3:391-5.

2 Pefoyo AJK, Bronskill SE, Gruneir A, et al. The increasing burden and complexity of multimorbidity. BMC Public Health 2015;15:415.

3 Muth C, Blom JW, Smith SM, et al. Evidence supporting the best clinical management of patients with multimorbidity and polypharmacy: a systematic guideline review and expert consensus. J Intern Med 2019;285:272-88.

4 Bricca A, Harris LK, Jäger $M$, et al. Benefits and harms of exercise therapy in people with multimorbidity: a systematic review and meta-analysis of randomised controlled trials. Ageing Res Rev 2020;63:101166.

5 GBD 2019 Diseases and Injuries Collaborators. Global burden of 369 diseases and injuries in 204 countries and territories, 1990-2019: a systematic analysis for the global burden of disease study 2019. Lancet 2020;396:1204-22. 